\title{
ON A DEFINITION OF ABSTRACT GROUPS*
}

\author{
BY \\ ELIAKIM HASTINGS MOORE
}

In a paper entitled $A$ definition of abstract groups (Transactions, vol. 3, pp. 485-492, October, 1902), my second definition (l. c., p. 490)

$$
\left(M^{\prime \prime}\right)=\left(1,2,3^{\prime}, 3_{\prime \prime}^{\prime \prime}, 3_{r}^{\prime \prime}, 4_{\imath}^{\prime \prime}\right)
$$

involves postulates not mutually independent. I shall prove here (as stated in October, 1904, Transaction s, vol. 5, p. 549) that $\left(3_{r}^{\prime \prime}\right)$ is redundant, that in the new definition

$$
\left(\bar{M}^{\prime \prime}\right):\left(1,2,3^{\prime \prime}, 3_{\imath}^{\prime \prime}, 4_{\imath}^{\prime \prime}\right)
$$

the postulates are mutually independent, and that this mutual independence remains even for the system

$$
\left(\bar{M}_{\Delta}^{\prime \prime}\right):\left(1,2,3^{\prime \prime}, 3_{\imath}^{\prime \prime}, 4_{\imath}^{\prime \prime}, A\right)
$$

defining an abelian group, obtained by adding to those of $\left(M^{\prime \prime}\right)$ the postulate $(A)$ that the multiplication or composition of two elements is commutative.

We have for consideration a set $\dagger$ or class $(K)$ of elements and a multiplication-table or rule of combination (o) whereby to every two elements $a, b$ taken in the definite order $a, b$ there corresponds a definite so-called product, in notation $a \circ b$, or, when without confusion, more simply, $a b$; this product may or may not be an element of the class. The postulates in qnestion are then the following:

(1) If $a$ and $b$ are elements, then $a b$ is an element of the class.

(A) If $a$ and $b$ are elements such that $a b$ and $b a$ are elements, then $a b=b a$.

(2) If $a, b, c$ are elements such that $a b, b c,(a b) c, a(b c)$ are elements, then $(a b) c=a(b c)$.

$\left(3^{\prime \prime}\right)$ There exists an element $a$ such that $a a=a$.

$\left(3_{l}^{\prime \prime}\right)$ If $a$ and $b$ are elements and $a a=a$, then $a b=b$.

$\left(3_{r}^{\prime \prime}\right)$ If $a$ and $b$ are elements and $a a=a$, then $b a=b$.

$\left(4_{l}^{\prime \prime}\right)$ If $a$ and $b$ are elements and $a a=a$, then there exists an element $b_{l}^{(n)}$ such that $b_{l}^{(a)} b=a$.

* Presented to the Society December 30, 1904. Received for publication March 17, 1905.

$\dagger$ In the first definition $(M)$ there was the underlying understanding (1. c., p. 485, footuote $\ddagger$ ) or postulate $(0)$ that the class contain at least one element, and this carried over by implication to $\left(M^{\prime \prime}\right)$, where however in view of $\left(3^{\prime \prime}\right)$ it was not needed; it is now omitted. 
If $a$ is an element such that $a a=a$ we designate those parts of $\left(3_{l}^{\prime \prime}\right),\left(3_{r}^{\prime \prime}\right)$, $\left(4_{l}^{\prime \prime}\right)$ which refer to the element $a$ by $\left(3_{l}^{\prime \prime a}\right),\left(3_{r}^{\prime \prime a}\right),\left(4_{l}^{\prime \prime a}\right)$ respectively. Then we prove that $\left(3_{r}^{\prime \prime}\right)$ is deducible from $\left(1,2,3^{\prime \prime}, 3_{l}^{\prime \prime}, 4_{l}^{\prime \prime}\right)$ in that we prove that $\left(3_{r}^{\prime \prime a}\right)$ is deducible froon $\left(1,2,3_{l}^{\prime \prime a}, 4_{l}^{\prime \prime a}\right)$. This fact is proved by a suitable modification of the method used p. 486, $7^{\circ}$ loc. cit. If $a$ and $b$ are elements and $a a=a$, then we designate by $b^{\prime}, b^{\prime \prime}$ elements, which by $\left(4_{l}^{\prime \prime} a\right)$ surely exist, such that $b^{\prime} b=a, b^{\prime \prime} b^{\prime}=a$ and have in virtue of $\left(1,2,3_{l}^{\prime \prime} a\right)$ the continued equality,

$$
b a=b b^{\prime} b=a b b^{\prime} b=b^{\prime \prime} b^{\prime} b b^{\prime} b=b^{\prime \prime} a b^{\prime} b=b^{\prime \prime} b^{\prime} b=a b=b,
$$

that is, $b a=b$, which was to be proved. *

The proof that the postulates of $\left(\bar{M}_{A}^{\prime \prime}\right)$ are independent covers the independence of the postulates of $\left(\bar{M}^{\prime \prime}\right)$ and appears from the following proof systems $(K$, o):

For (1). $K=$ all integers $0, \pm 1, \pm 2, \ldots$ except $\pm 1 . \quad 0=+$.

For (2). $K=$ an element $a$ and any class of (at least three) elements $x$ distinct from $a$. $\quad a \circ a=a . \quad a \circ x=x \circ a=x . \quad x_{1} \circ x_{2}=a$ if $x_{1} \neq x_{2}$; $x_{1} \circ x_{1}=x_{3}$ where, for every $x_{1}, x_{3}$ is any $x$ except $x_{1}$.

For $\left(3^{\prime \prime}\right) . \quad K=$ all positive integers. $\quad 0=+$.

For $\left(3_{l}^{\prime \prime}\right) . \quad K=\mathrm{a}$ class of (at least two) elements $x . \quad x_{1} \circ x_{2}=a$, where $a$ is a definite element, the same for all pairs $x_{1}, x_{2}$.

For $\left(4_{l}^{\prime \prime}\right) . \quad K=$ all positive integers and $0 . \quad 0=+$.

For $(A) . \quad(K$, o $)=$ any non-abelian group.

The UNIVERSITY OF Chicago.

* [ A second continued equality

$$
b a=a b a=b^{\prime \prime} b^{\prime} b a=b^{\prime \prime} a a=b^{\prime \prime} a=b^{\prime \prime} b^{\prime} b=a b=b
$$

should be noticed.] 